Article

\title{
Developing a Universal and Efficient Method for the Rapid Selection of Stable Fluorescent Protein-Tagged Pathogenic Vibrio Species
}

\author{
Candice A. Thorstenson (1) and Matthias S. Ullrich * \\ Department of Life Sciences and Chemistry, Jacobs University Bremen, 28759 Bremen, Germany; \\ c.thorstenson@jacobs-university.de \\ * Correspondence: m.ullrich@jacobs-university.de
}

Received: 25 September 2020; Accepted: 13 October 2020; Published: 16 October 2020

\begin{abstract}
World-wide increases in Vibrio-associated diseases have been reported in aquaculture and humans in co-occurrence with increased sea surface temperatures. Twelve species of Vibrio are known to cause disease in humans, but three species dominate the number of human infections world-wide: Vibrio cholerae, Vibrio parahaemolyticus, and Vibrio vulnificus. Fluorescent protein (FP)-labelled bacteria have been used to make great progress through in situ studies of bacterial behavior in mixed cultures or within host tissues. Currently, FP-labelling methods specific for Vibrio species are still limited by time-consuming counterselection measures that require the use of modified media and temperatures below the optimal growth temperature of many Vibrio species. Within this study, we used a previously reported R6K-based suicide delivery vector and two newly constructed transposon variants to develop a tailored protocol for FP-labelling $V$. cholerae, V. parahaemolyticus, and V. vulnificus environmental isolates within two days of counterselection against the donor Escherichia coli. This herein presented protocol worked universally across all tested strains (30) with a conjugation efficiency of at least two transconjugants per 10,000 recipients.
\end{abstract}

Keywords: fluorescent protein; Vibrio; pathogen; selective culture; transposon

\section{Introduction}

Members of the genus Vibrio are heterotrophic gammaproteobacteria, found in fresh water and marine ecosystems across the world. Several Vibrio species are relatively easy to culture in comparison with other marine bacteria and have been key to understanding symbiotic relationships [1]. Many Vibrio species are pathogens of not only key aquaculture stocks such as mollusks and fish, but humans as well. Three known human-pathogenic species, V. cholerae, V. parahaemolyticus, and V. vulnificus, cause the most seawater and seafood associated infections in humans world-wide [2,3]. Due to their importance to human health and the potential spread of pathogenic genes amongst environmental isolates, there is great interest in using both environmental and clinical strains of these bacteria for in situ behavioral studies. Tagging or labelling microorganisms with fluorescent protein has long been a valuable approach and allows for the tracking of the labelled organism's growth and behavior in mixed cultures or when cultivated with a host symbiont $[4,5]$.

Relatively few marine bacteria have been tagged with fluorescent proteins. As such, method development for genetically modifying marine bacteria, especially Vibrio species, has received increased attention in recent years. As reviewed by Zeaiter et al. [6], multiple studies report various methods for the genetic modification of Vibrios, but often with unstated efficiencies or universality between strains of the same species. Chemical transformation and electroporation of V. cholerae, $V$. parahaemolyticus, and $V$. vulnificus have been demonstrated, but these protocols often are limited 
to specific strains, and are reported with poor or negative results [7-10]. Cultivating V. cholerae, $V$. parahaemolyticus, and $V$. vulnificus with chitin has been reported to make the cells naturally competent to take up plasmid DNA via transformation [11-14]. However, both natural and artificial transformations can be ineffective depending on the bacterial strain of interest and the transferred DNA [15], with one method performing well within one strain but not another strain of the same species. As an alternative, bacterial conjugation can be used to genetically manipulate strains that are otherwise resistant to transformation [6]. For example with Vibrio splendidus strain LGP32, electroporation failed whereas conjugation with an E. coli donor strain produced several mutants [16].

One of the main challenges in bi- or tri- parental conjugation procedures is the counterselection for the recipient versus the E. coli donor. Sawabe et al. [17], used selective media and low temperatures $\left(15^{\circ} \mathrm{C}\right)$ to counter-select against the E. coli host. Travers et al. [18], used a combination of flow cytometry cell-sorting and epifluorescence microscopy to differentiate GFP-tagged Vibrio harveyi and the donor GFP-tagged E. coli cells.

Maintaining plasmid stability, and thereby GFP expression, without antibiotic selection, can limit the usefulness of GFP-tagged Vibrios in downstream applications. Studies which combined GFP cassettes with plasmids that are retained without antibiotic selection have led to an understanding of Vibrio disease dynamics in fish, squid, and mollusks [18-21]. However, the stability of GFP expression in these plasmid-carrying Vibrios varies based on nutrient conditions and the species or strain involved, with the best expression visualized within two to four days without selection [17,19].

Our aim was to develop a method to stably FP-label Vibrio bacteria for long-term cultivation without the use of antibiotics. We report the use of R6K-based suicide delivery vectors to develop a tailored and universal method for the fast FP-tagging of V. cholerae, V. parahaemolyticus, and V. vulnificus environmental strains, with a simplified counterselection procedure. We demonstrated the usefulness of an already established suicide vector [22] for labelling multiple strains of V. cholerae, V. parahaemolyticus, and $V$. vulnificus, as well as constructed two new variants carrying either red fluorescent protein (RFP) or cyano fluorescent protein (eCFP) genes, and a chloramphenicol resistance cassette $\left(\mathrm{Cm}^{\mathrm{R}}\right)$. We obtained transconjugants from all tested strains within two days at $28^{\circ} \mathrm{C}$ with an efficiency of producing two transconjugants per 10,000 Vibrio recipient cells. In downstream applications, we found that the newly constructed transposons are suitable for promoter-probing and for producing stably labelled Vibrio clones that were comparative to their wild-type (WT) strain under nutrient-limited conditions.

\section{Materials and Methods}

The bacterial strains and species, and their relevant characteristics, used for the conjugation experiments are listed in Table 1. Most of the Vibrio strains are recent North Sea isolates, collected from either the water column or phytoplankton samples, with exceptions noted. One V. parahaemolyticus strain was acquired from the German Central Culture Collection (DSMZ) and cannot be considered a recent environmental isolate, was used to validate the FP-labelling method. All wild-type (WT) Vibrio strains were reactivated from a $15 \%$ glycerol stock (stored at $-80^{\circ} \mathrm{C}$ ) before the conjugations to ensure minimal mutation accumulation. $V$. cholerae and $V$. vulnificus were cultivated with the use of Marine Broth (MB) agar or liquid medium [23]. V. parahaemolyticus was cultivated on LB agar to prevent the swarming of colonies. Antibiotic concentrations were used at the following concentrations: ampicillin (Ap), $50 \mu \mathrm{g} \mathrm{mL}^{-1}$; kanamycin $(\mathrm{Km}), 50 \mu \mathrm{g} \mathrm{mL}^{-1}$; gentamycin $(\mathrm{Gm}), 50 \mu \mathrm{g} \mathrm{mL}^{-1}$ for $V$. cholerae and V. parahaemolyticus and $75 \mu \mathrm{g} \mathrm{mL} \mathrm{g}^{-1}$ for V. vulnificus; and chloramphenicol (Cm), $20 \mu \mathrm{g} \mathrm{mL} \mathrm{L}^{-1}$ for the E. coli donor strains, $10 \mu \mathrm{g} \mathrm{mL} \mathrm{m}^{-1}$ for the Vibrio recipient strains. E. coli strains were routinely grown in LB broth, supplemented with antibiotics when appropriate. Additionally, E. coli ST18 always required the addition of 5-aminolevulinic acid (5-ALA) with a final concentration of $50 \mu \mathrm{g} \mathrm{mL}^{-1}$ for growth. 
Table 1. Bacterial Strains and Species. ID Number corresponds to the numbering used throughout this study, the strain number refers to the strain's entry in the VibrioNet database (VibrioNet Europe) at the Biological Institute Helgoland or the identification number from the German Collection of Microorganisms and Cell Cultures (DSMZ).

\begin{tabular}{|c|c|c|c|c|}
\hline Species & ID Number & $\begin{array}{l}\text { Strain } \\
\text { Number }\end{array}$ & Isolation Source & Source \\
\hline E. coli CC118 ( $\lambda$ pir) & - & - & - & [24] \\
\hline E. coli PIR-1 & - & - & - & $\begin{array}{l}\text { Thermofischer Scientific, } \\
\text { Cat. no. C101010 }\end{array}$ \\
\hline E. coli ST18 & - & - & - & [23] \\
\hline E. coli S17-1 & - & - & - & M.F. Alexeyev \\
\hline V. cholerae & Vc-1 & VN-03213 & North Sea Water & this study \\
\hline V. cholerae & $V_{c}-2$ & VN-04051 & Clinical isolate & this study \\
\hline V. cholerae & Vc-3 & VN-04216 & North Sea Water & this study \\
\hline V. cholerae & Vc-4 & VN-04219 & North Sea Water & this study \\
\hline V. cholerae & Vc-5 & VN-04223 & North Sea Water & this study \\
\hline V. cholerae & Vc-6 & VN-04226 & North Sea Water & this study \\
\hline V. cholerae & Vc-7 & VN-04233 & North Sea Water & this study \\
\hline V. cholerae & Vc-8 & VN-04261 & North Sea Water & this study \\
\hline V. cholerae & Vc-9 & VN-10012 & unknown & this study \\
\hline V. cholerae & Vc-10 & VN-10013 & unknown & this study \\
\hline V. parahaemolyticus & Vp-11 & VN-02509 & $\begin{array}{c}\text { North Sea } \\
\text { Phytoplankton }\end{array}$ & this study \\
\hline V. parahaemolyticus & Vp-12 & VN-02537 & $\begin{array}{l}\text { North Sea } \\
\text { Zooplankton }\end{array}$ & this study \\
\hline V. parahaemolyticus & Vp-13 & VN-02538 & $\begin{array}{l}\text { North Sea } \\
\text { Mytilus edulis }\end{array}$ & this study \\
\hline V. parahaemolyticus & Vp-14 & VN-02989 & North Sea Water & this study \\
\hline V. parahaemolyticus & Vp-15 & VN-03220 & North Sea Water & this study \\
\hline V. parahaemolyticus & Vp-16 & VN-03257 & North Sea Water & this study \\
\hline V. parahaemolyticus & Vp-17 & VN-03653 & $\begin{array}{c}\text { North Sea } \\
\text { Crassostrea gigas }\end{array}$ & this study \\
\hline V. parahaemolyticus & Vp-18 & VN-03747 & $\begin{array}{c}\text { North Sea } \\
\text { Crassostrea gigas }\end{array}$ & this study \\
\hline V. parahaemolyticus & Vp-19 & VN-03857 & English Channel & this study \\
\hline$V$. parahaemolyticus & $\mathrm{Vp}-20$ & VN-04006 & North Sea Water & this study \\
\hline V. parahaemolyticus & Vp-DSMZ & DSM-11058 & United Kingdom & [25] \\
\hline V. vulnificus & Vv-21 & VN-03373 & North Sea Water & this study \\
\hline V. vulnificus & Vv-23 & VN-03451 & North Sea Water & this study \\
\hline V. vulnificus & $\mathrm{Vv}-24$ & VN-03467 & North Sea Water & this study \\
\hline V. vulnificus & Vv-25 & VN-03949 & North Sea Water & this study \\
\hline V. vulnificus & Vv-26 & VN-02813 & North Sea Water & this study \\
\hline V. vulnificus & Vv-27 & VN-03110 & $\begin{array}{c}\text { North Sea, } \\
\text { Phytoplankton }\end{array}$ & this study \\
\hline V. vulnificus & Vv-28 & VN-03369 & North Sea Water & this study \\
\hline V. vulnificus & Vv-29 & VN-03478 & North Sea Water & this study \\
\hline V. vulnificus & Vv-30 & VN-03478 & North Sea Water & this study \\
\hline
\end{tabular}




\subsection{Construction of RFP and eCFP Suicide Vectors}

A summary of the vectors utilized in this project can be found in Table 2. All enzymes came from New England Biolabs (NEB) and were used according to the manufacturer's instructions. The atpE, $g f p$, and aphA-3 (kanamycin resistance, $\mathrm{Km}^{\mathrm{R}}$ ) genes (1650 bp) from pAG408 [22] were excised from the vector backbone with a KpnI (NEB \#R3142S) digest, the digest was run on a one percent agarose/TBE gel for $45 \mathrm{~min}$ at $120 \mathrm{~V}$. The vector backbone was extracted and processed with GeneJET Gel Extraction and DNA Cleanup Kit (ThermoFisher Scientific, Waltham, MA, USA, \#K0831). The backbone was then re-circulated using T4 DNA Ligase (NEB \#M0202) and transformed via heat-shock into E. coli S17-1, producing pAG-SC. E. coli S17-1 colonies containing pAG-SC were selected for with Gm and Ap. Single colonies were cultured in LB broth supplemented with antibiotics and plasmids were isolated via GeneJET Plasmid Miniprep Kit (ThermoFisher Scientific, Waltham, MA, USA, \#K0502).

Table 2. Vectors used for Cloning and FP-labelling in E. coli and Vibrio species.

\begin{tabular}{|c|c|c|c|}
\hline Vector Name & Description & Relevant Characteristics & Study \\
\hline pBBR1MCS4- eCFP.cat & $\begin{array}{c}\text { Source of the eCFP and } \mathrm{Cm}^{\mathrm{R}} \\
\text { genes }\end{array}$ & $\mathrm{eCFP}, \mathrm{Cm}^{\mathrm{R}}, \mathrm{Ap}^{\mathrm{R}}$ & {$[26,27]$} \\
\hline $\begin{array}{c}\text { pBBR1MCS4- } \\
\text { dsRedExpress.cat }\end{array}$ & $\begin{array}{l}\text { Source of the DsRedExpress } \\
\text { and } \mathrm{Cm}^{\mathrm{R}} \text { genes }\end{array}$ & $\begin{array}{c}\text { DsRedExpress, } \mathrm{Cm}^{\mathrm{R}}, \\
\mathrm{Ap}^{\mathrm{R}}\end{array}$ & {$[26,27]$} \\
\hline pAG408 & $\begin{array}{l}\text { Suicide vector, } \\
\text { requires presence of } \lambda \text { pir-1 } \\
\text { gene in host to replicate }\end{array}$ & $\mathrm{GFP}, \mathrm{Km}^{\mathrm{R}}, \mathrm{Gm}^{\mathrm{R}}, \mathrm{Ap}^{\mathrm{R}}$ & [22] \\
\hline pAG-SC & $\begin{array}{l}\text { Backbone of } \mathrm{pAG} 408, \\
\text { with the } a t p E, \mathrm{GFP} \text {, and } \mathrm{Km}^{\mathrm{R}} \\
\text { regions excised }\end{array}$ & $\mathrm{Gm}^{\mathrm{R}}, \mathrm{Ap}^{\mathrm{R}}$ & this study \\
\hline pCAT14 & $\begin{array}{l}\text { eCFP and } \mathrm{Cm}^{\mathrm{R}} \text { genes cloned } \\
\text { into pAG-SC }\end{array}$ & $\mathrm{eCFP}, \mathrm{Cm}^{\mathrm{R}}, \mathrm{Gm}^{\mathrm{R}}, \mathrm{Ap}^{\mathrm{R}}$ & this study \\
\hline pCAT30 & $\begin{array}{l}\text { DsRedExpress and } \mathrm{Cm}^{\mathrm{R}} \\
\text { genes cloned into pAG-SC }\end{array}$ & $\begin{array}{l}\text { DsRedExpress, } \mathrm{Cm}^{\mathrm{R}}, \\
\mathrm{Gm}^{\mathrm{R}}, \mathrm{Ap}^{\mathrm{R}}\end{array}$ & this study \\
\hline pBluescriptII SK ${ }^{+}$ & $\begin{array}{c}\text { Cloning vector for } \\
\text { sequencing of the transposon }\end{array}$ & $\mathrm{Ap}^{\mathrm{R}}$ & - \\
\hline ML_04 & $\begin{array}{l}\text { Transposon region from } \\
\text { pCAT14 cloned into } \\
\text { pBluescriptII SK }\end{array}$ & $\mathrm{eCFP}, \mathrm{Cm}^{\mathrm{R}}, \mathrm{Gm}^{\mathrm{R}}, \mathrm{Ap}^{\mathrm{R}}$ & this study \\
\hline ML_6.2 & $\begin{array}{l}\text { Transposon region from } \\
\text { pCAT30 cloned into } \\
\text { pBluescriptII SK }\end{array}$ & $\begin{array}{l}\text { DsRedExpress, } \mathrm{Cm}^{\mathrm{R}}, \\
\mathrm{Gm}^{\mathrm{R}}, \mathrm{Ap}^{\mathrm{R}}\end{array}$ & this study \\
\hline ML_02 & $\begin{array}{l}\text { Transposon region from } \\
\text { VcR-7-2 (clone 120) inserted } \\
\text { into pBluescriptII SK }\end{array}$ & $\begin{array}{l}\text { DsRedExpress, } \mathrm{Cm}^{\mathrm{R}} \text {, } \\
\qquad \mathrm{Gm}^{\mathrm{R}}, \mathrm{Ap}^{\mathrm{R}}\end{array}$ & this study \\
\hline ML_12 & $\begin{array}{l}\text { Transposon region from } \\
\text { VvR-21 (clone150) inserted } \\
\text { into pBluescriptII SK }\end{array}$ & $\begin{array}{l}\text { DsRedExpress, } \mathrm{Cm}^{\mathrm{R}} \text {, } \\
\qquad \mathrm{Gm}^{\mathrm{R}}, \mathrm{Ap}^{\mathrm{R}}\end{array}$ & this study \\
\hline
\end{tabular}

The DsRedExpress.cat and eCFP.cat gene sequences (each approximately $2000 \mathrm{bp}$ ) were obtained from previously constructed pBBR1MCS4 -based vectors [26], via digestion of the plasmid with NotI (NEB \#R3189S). Then the $2000 \mathrm{bp}$ fragments were subsequently excised and gel-extracted in the same manner as above. The empty vector pAG-SC was opened with NotI and ligated with the excised DsRedExpress.cat and eCFP.cat, respectively, before being transformed into commercially available $E$. coli PIR-1 cells (ThermoFisher Scientific, Waltham, MA, USA, \#C101010) as per the manufacturer's instructions. This produced two vectors which were re-isolated from the PIR-1 cells (GeneJet plasmid miniprep kit, ThermoFisher \#K0502) and electroporated into E. coli ST18 via the method as described 
by [28]. The resulting vectors, pCAT30 (carrying DsRedExpress.cat) and pCAT14 (carrying eCFP.cat) both kept the pAG408 original backbone as well as the beginning and ending constructs within the transposon region [22]. The transposon region now encodes for either RFP, encoded by DsRedExpress, or eCFP in place of GFP, and the $\mathrm{Cm}^{\mathrm{R}}$ gene in place of the aphA-3 gene as illustrated in Figure 1. The original pAG408 vector [22] was additionally electroporated into E. coli ST18 to serve as a positive control. Thus three E. coli ST18 host strains carrying either pAG408, pCAT30, or pCAT14 were used in subsequent conjugation experiments with the Vibrio recipients.

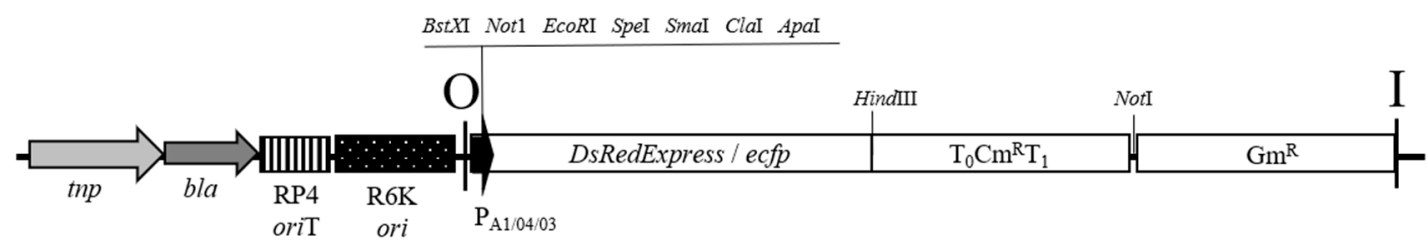

Figure 1. Schematic representation of the cloning vectors pCAT14 (ecfp) and pCAT30 (DsRedExpress). Adapted from [22]: tnp, Tn5 transposase; bla, lactamase encoding gene; oriT RP4, transfer origin; ori $\mathrm{R} 6 \mathrm{~K}$, origin of replication; I and $\mathrm{O}$, inner and outer ends of IS50; and $\mathrm{Gm}^{\mathrm{R}}$, the gentamycin resistance gene. The $\mathrm{P}_{\mathrm{A} 1 / 04 / 03}$ constitutive promoter, DsRedExpress or eCFP genes, and $\mathrm{T}_{0} C \mathrm{~m}^{\mathrm{R}} \mathrm{T}_{1}$ sequences are as described by [27]. Useful, known restriction sites are indicated. The figure is not drawn to scale.

\subsection{Plasmid Conjugation in Vibrio}

The suicide vectors pAG408, pCAT14, and pCAT30 were transferred to the $V$. cholerae, $V$. parahaemolyticus, and $V$. vulnificus recipient strains via bi-parental mating with $E$. coli ST18 carrying pAG408, pCAT30, or pCAT14. A target donor-to-recipient ratio of ten-to-one was favored for obtaining Vibrio transconjugants. An overnight culture of $10-30 \mathrm{~mL}$ was inoculated with 1-3 colonies from each vector-containing E. coli ST18 and Vibrio strain in LB (supplemented with 5-ALA) and MB broth, respectively. Once the E. coli ST18 cultures reached an $\mathrm{OD}_{600}$ of 1.5 to 2.0, one milliliter of overnight E. coli culture was spun down per Vibrio recipient in a $1.5 \mathrm{~mL}$ centrifuge cup at $11,000 \times \mathrm{g}$ for two minutes. This led to a starting concentration of approximately $10^{8} \mathrm{E}$. coli cells per milliliter. The E. coli pellet was washed once with $0.5 \mathrm{~mL}$ LB supplemented with 5-ALA broth. The overnight cultures of Vibrio were diluted to an $\mathrm{OD}_{600}$ of 0.5 , and from this, $0.1 \mathrm{~mL}$ was added to the pelleted E. coli and the suspension was pelleted again at $11,000 \times g$ for another minute. The pellet was resuspended in $10 \mu \mathrm{L} \mathrm{LB}$ and 5-ALA, then all of the resuspension was applied in a single spot on a LB agar plate supplemented with 5-ALA. These spot plates were incubated for $20 \pm 2 \mathrm{~h}$ at $20^{\circ} \mathrm{C}$. Each conjugation was performed in triplicate.

The following day, each spot was scraped off the plate and resuspended in one milliliter MB broth. The resuspension was serially diluted (to $10^{-5}$ ) in $\mathrm{MB}$ broth and plated on the following: $\mathrm{MB} / \mathrm{LB}$ and Gm, LB and 5-ALA and Ap, and MB/LB agar without antibiotics. V. cholerae and V. vulnificus were always plated on MB agar and V. parahaemolyticus used LB agar. The last three dilutions were plated $\left(10^{-3}\right.$ through $\left.10^{-5}\right)$. In addition, controls consisting of only E. coli ST18 and Vibrio were plated on the same media to act as negative controls, along with a media -only negative control. All plates were incubated for up to five days at $28^{\circ} \mathrm{C}$. Transconjugants typically grew within the first two days, by the fifth day, the negative control plates began to have growth, and the experiment was terminated. Suspected transconjugants were picked and streaked for isolation on MB agar with Gm.

\subsection{PCR Confirmation of the Transconjugants}

All PCR amplifications were carried out with DNA Taq Polymerase from NEB according to the manufacturer's protocol. Primers and annealing temperatures are summarized in Table 3 . The recipient clones on the selective plates were re-confirmed as their suspected identity via a species-specific multiplex PCR [29]. Several clones per strain were chosen at random for further characterization on $\mathrm{MB}$ agar supplemented with $\mathrm{Gm}, \mathrm{Km}$, or $\mathrm{Cm}$ to check for the insertion of the pAG408 (selected with 
$\mathrm{Gm}$ and $\mathrm{Km}$ ) or pCAT30 and pCAT14 (selected with $\mathrm{Gm}$ or $\mathrm{Cm}$ ) transposons. Clones were evaluated for their fluorescence expression via standard epifluorescence techniques and were visualized on a Microscope AxioImager MTB2011 (Carl Zeiss Microscopy, Jena, Germany). Fluorescence was observed with the same exposure settings for all clones for GFP, eCFP, and RFP. Living bacterial cells were resuspended in $0.05 \%$ agarose droplets on slides to limit or prevent motility of the cells.

Table 3. PCR primers and annealing temperatures used in this study. All PCR amplification reactions utilized DNA Taq Polymerase and dNTPs provided by NEB via the manufacturer's instructions. The Vibrio species-specific primers were used in a multiplex PCR.

\begin{tabular}{|c|c|c|c|c|c|}
\hline Primer Name & Sequence $5^{\prime} \rightarrow 3^{\prime}$ & Target & Product Size & Source & $\begin{array}{l}\text { Annealing } \\
\text { Temperature }\end{array}$ \\
\hline pAG Tr FW & $\begin{array}{c}\text { GGG GTA CCC CGC } \\
\text { TCG AGT AAT TTA } \\
\text { CCA A }\end{array}$ & \multirow{2}{*}{$\begin{array}{l}\text { pAG408 } \\
\text { transposon }\end{array}$} & \multirow[b]{2}{*}{$1500 \mathrm{bp}$} & \multirow[b]{2}{*}{ [22] } & \multirow[b]{2}{*}{$57^{\circ} \mathrm{C}$} \\
\hline pAG Tr RV & $\begin{array}{c}\text { GGG GTA CCC CGC } \\
\text { TTT TTA GAC ATC } \\
\text { TAA ATC }\end{array}$ & & & & \\
\hline Vc ToxR 403F & $\begin{array}{c}\text { GAA GCT GCT CAT } \\
\text { GAC ATC }\end{array}$ & \multirow{2}{*}{$\begin{array}{l}\text { V. cholerae toxR } \\
\text { gene }\end{array}$} & \multirow[b]{2}{*}{$275 \mathrm{bp}$} & \multirow{6}{*}{ [29] } & \multirow{6}{*}{$55^{\circ} \mathrm{C}$} \\
\hline Vc ToxR 678R & $\begin{array}{c}\text { AAG ATC AAG GGT } \\
\text { GGT TAT TC }\end{array}$ & & & & \\
\hline Vp ToxR 325F & $\begin{array}{c}\text { TGT ACT GTT GAA } \\
\text { CGC CTA A }\end{array}$ & \multirow{2}{*}{$\begin{array}{c}V . \\
\text { parahaemolyticus } \\
\text { toxR gene }\end{array}$} & \multirow{2}{*}{$503 \mathrm{bp}$} & & \\
\hline Vp ToxR 828R & $\begin{array}{c}\text { CAC GTT CTC ATA } \\
\text { CGA GTG }\end{array}$ & & & & \\
\hline VvhA 870F & $\begin{array}{c}\text { CAC TCA ACT ATC } \\
\text { GTG CAC G }\end{array}$ & \multirow{2}{*}{$\begin{array}{l}V . \text { vulnificus } \\
\text { hemolysin } \mathrm{A} \\
\text { gene }\end{array}$} & \multirow{2}{*}{$366 \mathrm{bp}$} & & \\
\hline VvhA 1236R & $\begin{array}{c}\text { ACA CTG TTC GAC } \\
\text { TGT GAG }\end{array}$ & & & & \\
\hline T3 & $\begin{array}{l}\text { AAT TAA CCC TCA } \\
\text { CTA AAG GG }\end{array}$ & \multirow{2}{*}{$\begin{array}{l}\text { Cloning region } \\
\text { in pBluescriptII }\end{array}$} & \multirow[b]{2}{*}{ varies } & \multirow[b]{2}{*}{-} & \multirow[b]{2}{*}{$50{ }^{\circ} \mathrm{C}$} \\
\hline $\mathrm{T} 7$ & $\begin{array}{c}\text { TAA TAC GAC TCA } \\
\text { CTA TAG GG }\end{array}$ & & & & \\
\hline
\end{tabular}

Since the WT Vibrio strains all displayed a high resistance to Km, an additional check for those clones labelled with pAG408 transposon was made via PCR amplification and detection of the pAG408 transposon (pAG Tr) using specific primers [22]. All PCRs utilized DNA Taq Polymerase (NEB \# M0273L) with the annealing temperatures listed in Table 3. All PCR products were visualized via gel electrophoresis on a one percent agarose gel and a run-time of $45 \mathrm{~min}$ at $120 \mathrm{~V}$.

\subsection{Comparative Analysis of RFP-Labelled Clones and the Wild-Type Strain}

Ten RFP-labelled clones were chosen for validation in comparison to the WT strain in sterile-filtered, autoclaved, North Sea water (NSW). A pre-culture was started with the inoculation of one colony in $10 \mathrm{~mL}$ MB broth supplemented with $\mathrm{Gm}$ for the clones (no antibiotic supplementation was used for the WT) and incubated at $28{ }^{\circ} \mathrm{C}$ with a shaking of $180 \mathrm{rpm}$ overnight. From this overnight culture, a serial dilution was made in NSW to obtain an $\mathrm{OD}_{600}$ of 0.1 . From this $\mathrm{OD}_{600}$ of 0.1 culture, $0.1 \mathrm{~mL}$ was further inoculated into $7 \mathrm{~mL}$ of NSW and incubated at $28^{\circ} \mathrm{C}$ for four days. A sub-sample of $0.1 \mathrm{~mL}$ was taken every $24 \mathrm{~h}$ and serially diluted and plated on MB agar plates supplemented with $\mathrm{Gm}$ for CFU enumeration, the WT were plated on non-selective plates. 


\subsection{Determination of the Transposon Location in Selected Clones}

The location of chromosomal insertion of the transposon was determined for two RFP-tagged clones, no. 120 (VcR-7-2) a V. cholerae clone, and no. 150 (VvR-21), a V. vulnificus clone. The chromosomal DNA from both clones was extracted via Monarch Genomic DNA purification kit (NEB, \#TS010). The chromosomal DNA was digested with HindIII and the whole digest was ligated with HindIII-opened pBluescriptII. The ligation mix (up to $5 \mu \mathrm{L}$ ) was transformed into E. coli PIR-1 cells via the manufacturer's instructions. The transformation was plated on $\mathrm{LB}$ agar containing $\mathrm{Gm}$ or $\mathrm{Cm}$. Individual colonies were picked and grown up under selection for plasmid extraction. A PCR amplification of the cloning region of pBluescriptII was made and all PCR products with sequenced via Eurofins genomics. The HindIII and vector sequences were cut-away, leaving the Vibrio chromosomal DNA sequences. These sequences were then compared with the BLAST (NCBI) database for nucleotide sequences.

\section{Results}

\subsection{Construction of New Suicide Vectors and Their Use in Vibrio Conjugation}

To optimize conjugation conditions, we initially tested several broad host range vectors as well as one suicide vector delivery system. We publish and discuss here only the method that reliably produced transconjugants across all three tested species. In our initial array of tested vectors, we were excited to see pAG408 $[22,30]$ labelled six strains of $V$. vulnificus (data not shown). The original conjugation protocol of pAG408 however, was not without its issues. First, the original E. coli CC118 host strain grew surprisingly well on $\mathrm{MB}$ agar at $28^{\circ} \mathrm{C}$, making counterselection and testing of the transconjugants a tedious endeavor. Second, the bi-parental mating did not transfer the pAG408 transposon to all of the tested strains. Third, when GFP was expressed, it was difficult to visualize via epifluorescence microscopy. Finally, most of our WT Vibrio isolates had a high tolerance to Km, making it a poor selection marker in this instance.

To begin to rectify these issues, the new cloning vectors PCAT14 and PCAT30, were constructed (Figure 1), which utilized the backbone of pAG408 and the DsRedExpress.cat and ecfp.cat genes described by [27]. The Tn5 region in pCAT14 and pCAT30 now carries the E. coli lac promoter, the eCFP or RFP gene (respectively), $\mathrm{Cm}^{\mathrm{R}}$, and $\mathrm{Gm}^{\mathrm{R}}$ genes. The E. coli $\mathrm{ST} 18$ host strain was used in place of CC118 to act as the donor of the vector, since its requirement for the addition of 5-ALA to the media for growth makes this particular strain easy to select against in conjugation experiments [23].

To test the FP-labelling ability of pAG408, pCAT14, and pCAT30, we performed a bi-parental mating with E. coli ST18 as the donor with three representative strains of $V$. cholerae, V. parahaemolyticus, and $V$. vulnificus (Figure 2). There was no significant difference in performance between the three vectors in these three representative strains. On average $10^{3}$ to $10^{5} \mathrm{CFU} \mathrm{mL} \mathrm{m}^{-1}$ transconjugants were enumerated from on the MB agar plates supplemented with antibiotics after conjugation. 


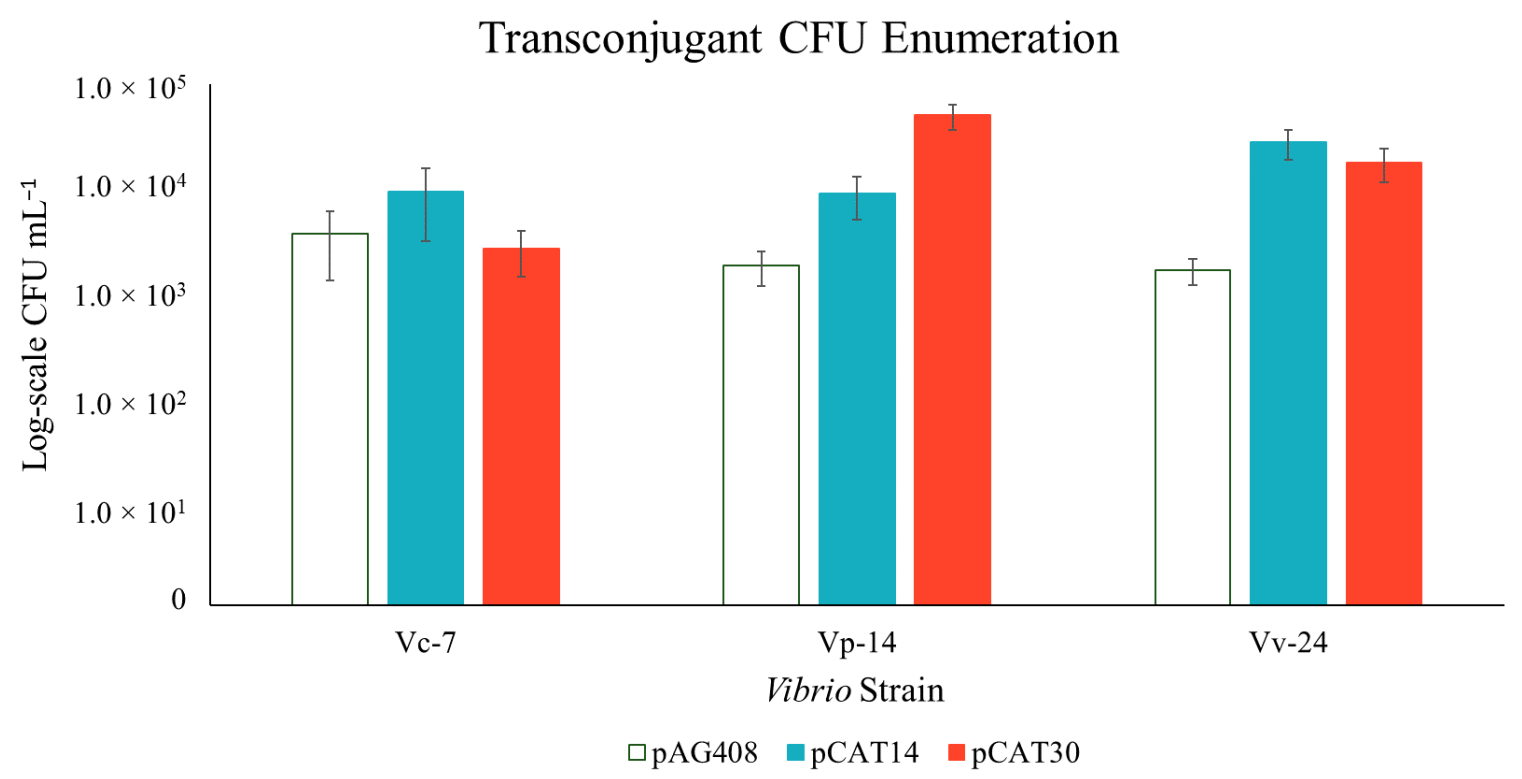

Figure 2. Transconjugant enumeration of Vibrio strains labeled with pAG408 (white), pCAT14 (blue), and pCAT30 (red). The labelling ability of the three suicide vectors were tested against three representative $V$. cholerae $(\mathrm{Vc})$, V. parahaemolyticus $(\mathrm{Vp})$, and $V$. vulnificus $(\mathrm{Vv})$ strains. Error bars represent the standard deviation between triplicates. Transconjugant enumeration was done on $\mathrm{MB}$ agar supplemented with $\mathrm{Gm}\left(50 \mu \mathrm{g} \mathrm{mL}^{-1}\right)$.

We further compared all three vectors in ten strains of $V$. cholerae. The three vectors behaved similarly to one another, with similar conjugation efficiency amongst the 10 strains (Figure 3). The total number of Vibrios recovered from the conjugation was enumerated from MB agar plates without supplementation. The average conjugation efficiency ( $\frac{\text { transconjugants }}{\text { total Vibrio }} \times 100$ ) across the $V$. cholerae strains (with the exclusion of strain Vc-6) was $0.02 \%$. When calculated for Vc-6 only, the efficiency was $1.4 \%$. Strain Vc-6 was treated as an outlier in the calculations because its growth behavior on the MB agar plates was considerably different than the other strains. Strain Vc-6 struggled to grow on MB medium and required double the incubation time for colonies to be enumerated. Vc- 6 also naturally produces a reddish pigment, which likely distorted the CFU. Here, we publish the results from $\mathrm{Vc}_{\mathrm{c}}-6$ to demonstrate that we were still able to label this strain, despite its clear difference from the other nine test strains but acknowledge that the high conjugation efficiency of this strain is unlikely. 


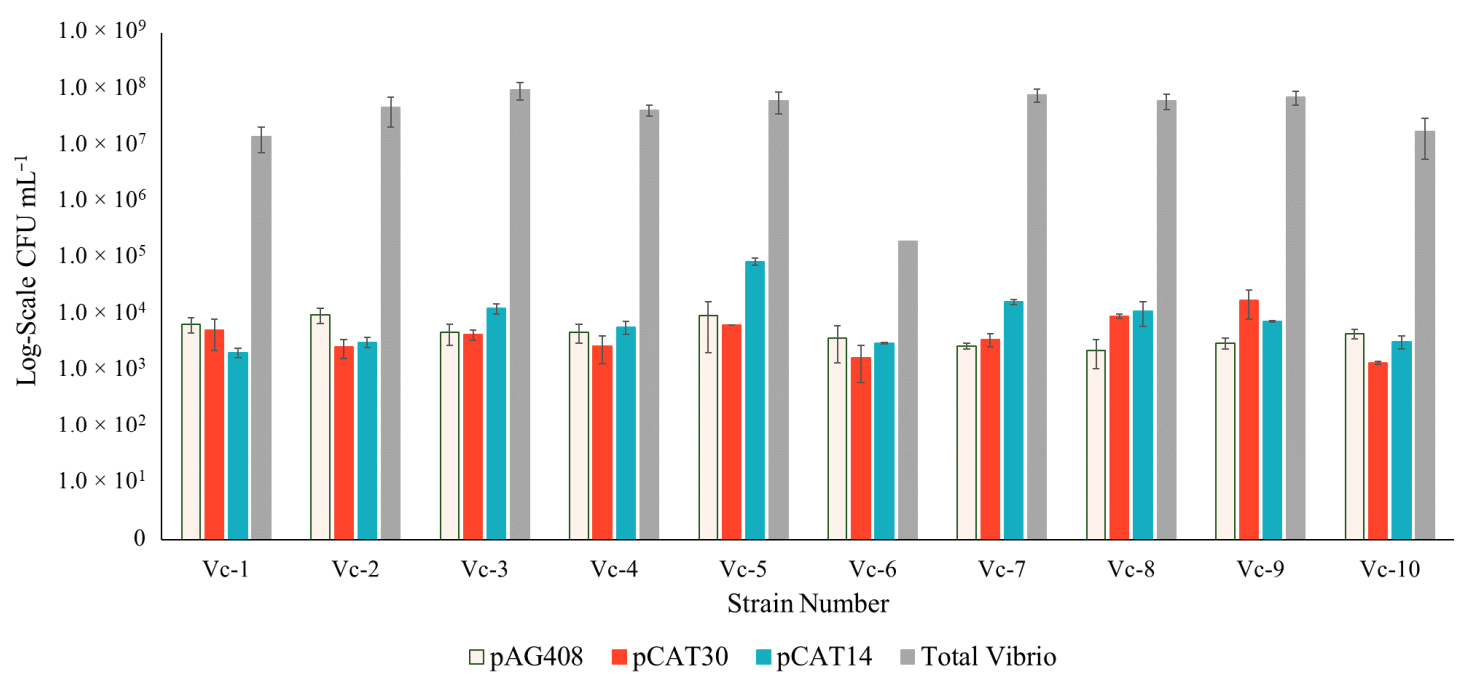

Figure 3. Transconjugant enumeration of $V$. cholerae strains labeled with pAG408 (white), pCAT14 (blue), and pCAT30 (red). The labelling efficiency of the three vectors was tested across all 10 strains of $V$. cholerae. The grey bars represent the total $V$. cholerae CFU enumeration from non-selective MB agar plates. Error bars represent the standard deviation between triplicate samples.

After the vectors were found to perform similarly in $\mathrm{Vp}-14, \mathrm{Vv}-24$, and the ten $V$. cholerae strains, pCAT30 was used to validate the labelling method in the remaining $V$. parahaemolyticus and $V$. vulnificus strains. Two minor changes to the protocol had to be made to achieve a similar efficiency to that of $V$. cholerae conjugations. The first was that $V$. parahaemolyticus needed cultivation on LB agar to be easily enumerated, the second was that the $V$. vulnificus clones needed to be selected with a final $\mathrm{Gm}$ concentration of $75 \mu \mathrm{g} \mathrm{mL}^{-1}$ in the media. Otherwise, the protocol remained the same as for $V$. cholerae strains. Like with the $V$. cholerae strains, the protocol produced transconjugants in all tested $V$. vulnificus and $V$. parahaemolyticus strains (Figures 4 and 5). The average conjugation efficiency for V. vulnificus and $V$. parahaemolyticus $(0.05 \%$ and $0.08 \%$, respectively) was slightly above that found for $V$. cholerae.

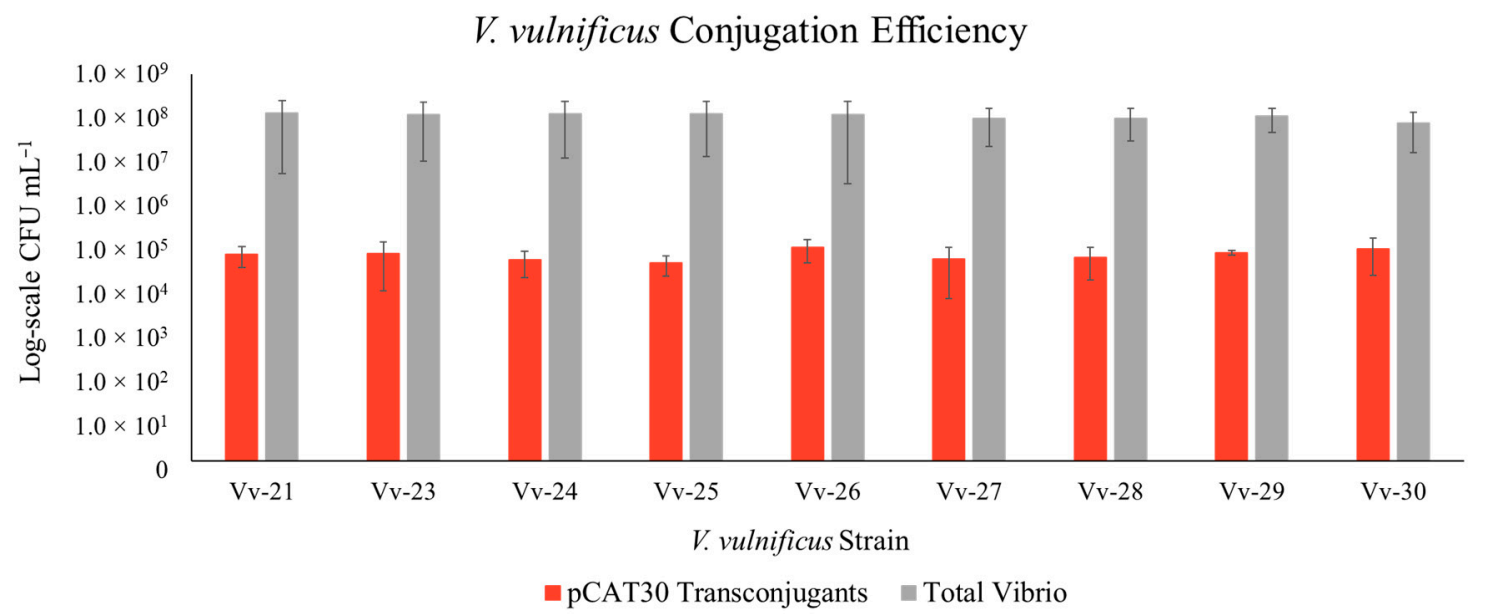

Figure 4. The conjugation efficiency of pCAT30 with $V$. vulnificus. Red bars represent the V. vulnificus transconjugants that grew on selective $\mathrm{MB}$ agar supplemented with $75 \mu \mathrm{g} \mathrm{mL} \mathrm{m}^{-1}$ and the grey bars represent the total Vibrio colonies enumerated on non-selective MB agar plates. 


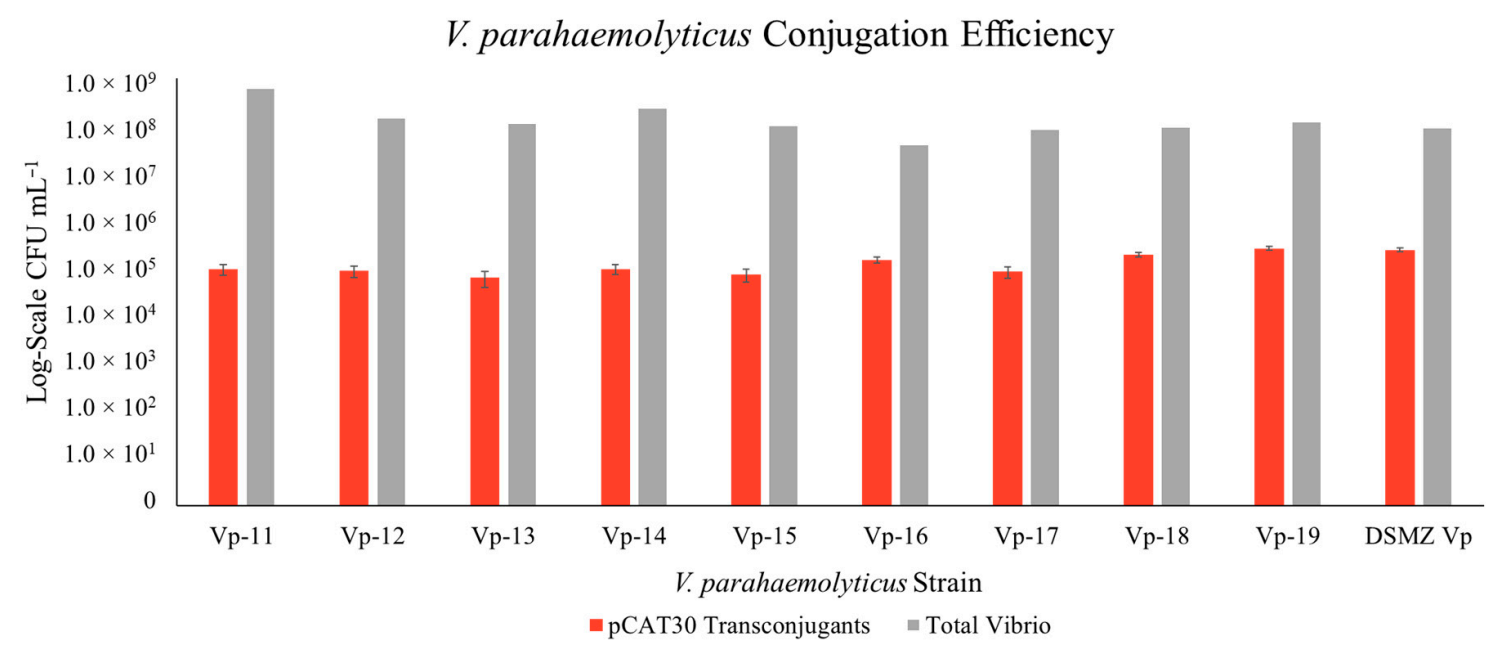

Figure 5. The conjugation efficiency of pCAT30 with $V$. parahaemolyticus. Red bars represent the $V$. parahaemolyticus transconjugants that grew on selective LB agar supplemented with $50 \mu \mathrm{g} \mathrm{mL}^{-1}$ and the grey bars represent the total Vibrio colonies enumerated on non-selective MB agar plates.

\subsection{Confirmation of the Transposon in the Vibrio Transconjugants}

The presence of the transposon in the transconjugants was confirmed via culturing on MB agar supplemented with multiple antibiotics and fluorescent microscopy. The $\mathrm{Gm}$ and $\mathrm{Cm}$ concentrations used did prevent the growth of the WT Vibrio strains; in addition, none of these WT strains were previously fluorescent. All transconjugants produced with pCAT30 and pCAT14 could grow on MB supplemented with $\mathrm{Gm}$ or $\mathrm{Cm}$. All pAG408 transconjugants could grow on MB supplemented with $\mathrm{Gm}$ and $\mathrm{Km}$, however, since a large number of our WT strains were resistant to $\mathrm{Km}$, an additional, in vitro detection of the pAG408 transposon was made via sequence-specific PCR amplification [22] as an additional confirmation.

To our knowledge, no Vibrio strain has the $\lambda$ pir-1 gene necessary for the replication of the vector backbone, thus the vector backbones from pAG408, pCAT14, and pCAT30 have not survived in the Vibrio hosts, leaving only the labelled transposon carrying the fluorescence gene, $\mathrm{Cm}$ or $\mathrm{Km}$, and $\mathrm{Gm}$ in the newly labelled Vibrio clones taken from selective media.

Fluorescence expression was quickly screened by resuspending a single colony from an agar plate and embedding in $0.05 \%$ agar or via growth in liquid medium overnight for $16 \mathrm{~h}$ and embedding on a glass slide. Not all Vibrio clones fluoresced equally, not even from the same strain. Some labelled clones had obvious phenotypic differences from their WT strain and each other, which were already visible on the agar plates wherein some clones expressed enough RFP that the strain had a reddish tint when grown on MB agar (Figure 6). This provides suggestive evidence that the E. coli promoter $\mathrm{P}_{\mathrm{A} 1 / 04 / 03}$ might not be constitutively expressed in Vibrio, and thusly, much like pAG408, the new vectors pCAT14 and pCAT30 will act as promoter probes in these species. 


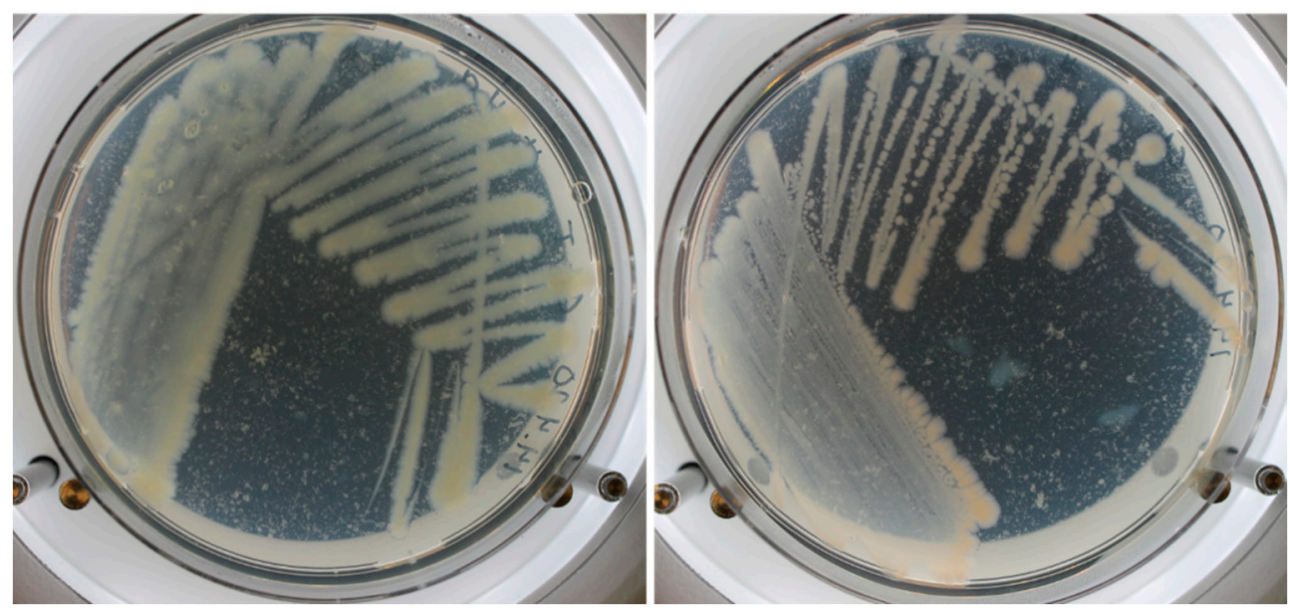

Figure 6. Wild-type $V$. cholerae strain Vc-7 and V. cholerae clone no. 120. Left: Wild-type strain; right: RFP-tagged $V$. cholerae clone no. 120. Clone 120 produces a slight reddish pigment in comparison to the WT strain after two day's growth, due to the strong RFP expression. Both the WT strain and clone were freshly struck from $15 \%$ glycerol stocks (frozen at $-80{ }^{\circ} \mathrm{C}$ ) onto $\mathrm{MB}$ agar without antibiotics. The plates were incubated at $37^{\circ} \mathrm{C}$ for two days. The plates are illuminated from the sides. Images taken from the lids of the plates.

We followed the performance of 10 clones and their corresponding WT strains in sterile NSW over a period of $72 \mathrm{~h}$. Three representative stable RFP-tagged clones which were comparable to the WT strain are shown in Figure 7. For eight out of ten clones, the final CFU mL ${ }^{-1}$ was comparable to the starting concentration. Indicating that we were quickly able to find labelled clones that were comparable to the WT strain when incubated in sterile NSW.

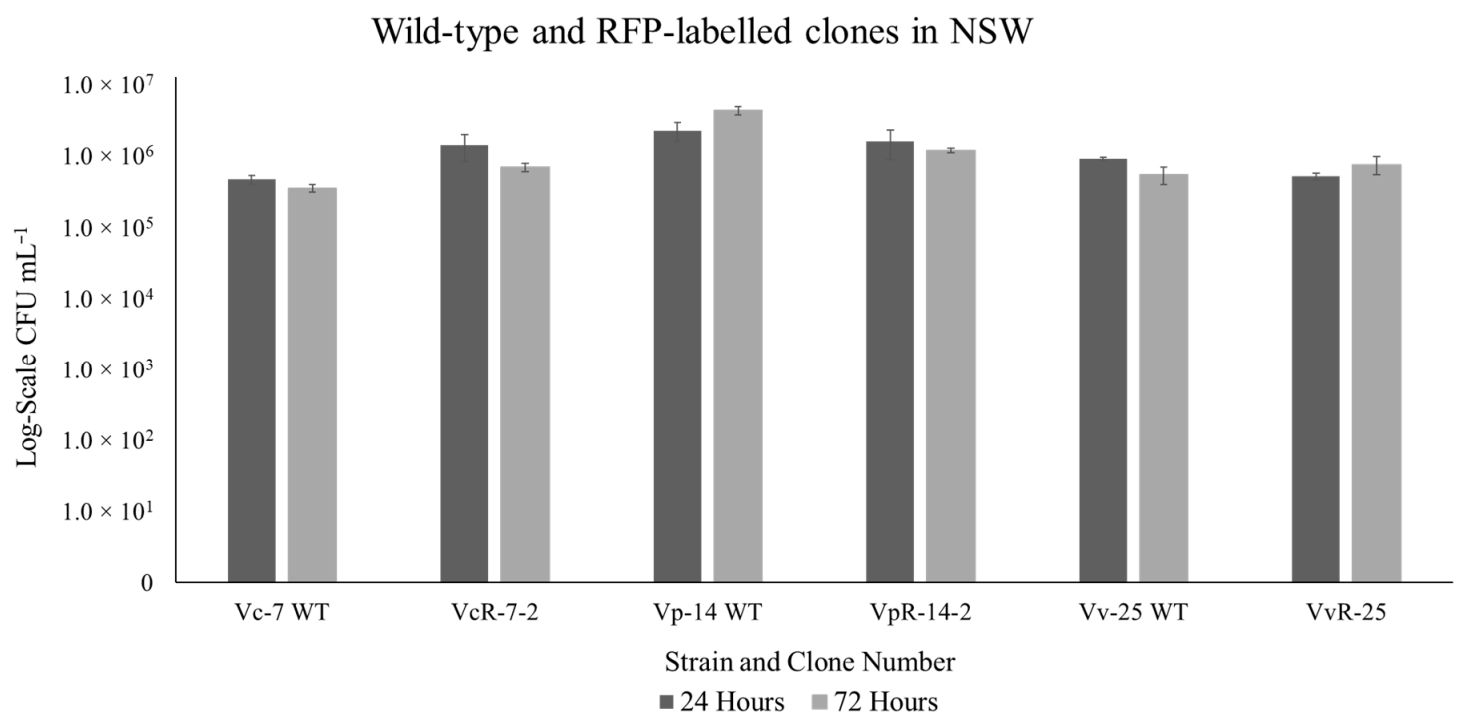

Figure 7. The stability of RFP-labelled Vibrio clones in sterile North Sea Water (NSW). Over 72 h, the RFP-tagged clones were tested in comparison to the corresponding wild-type (WT) strain. The CFU was enumerated on MB agar for the WT bacteria and MB agar supplemented with $50 \mu \mathrm{g} \mathrm{mL}^{-1}$ gentamycin for the RFP-tagged clone after $24 \mathrm{~h}$ (dark grey) and $72 \mathrm{~h}$ incubation (light grey) at $28^{\circ} \mathrm{C}$ in sterile NSW.

\subsection{Transposon Insertion in Target Vibrio}

The insert sites for the рСАТ30 transposon for one $V$. cholerae clone, clone no. 120 (WT strain Vc-7) and one V. vulnificus clone, clone no. 150 (WT strain Vv-21) were determined through digestion 
of chromosomal DNA extracts from the clones and subsequent cloning into a pBluescriptII vector. The T3 and T7 primers for pBluescriptII were then used to sequence the insertion in the cloning site of pBluescriptII.

From clone no. 120, the transposon inserted into chromosome I of $V$. cholerae. The sequence obtained from clone no. 120 was 232 nucleotides in length and showed high similarity $(100 \%$ nucleotide similarity) to the $V$. cholerae integron type 1 integrase (int1) gene (GenBank Accession \#ACC54438, \#KR262557) for the first 116 nucleotides. For the remaining 114 nucleotides, high similarity with V. cholerae Streptomycin 3"-adenylyltransferase (\#EAZ77748) and 100\% nucleotide similarity to V. cholerae rifampin ADP-ribosyl transferase (\#CFW11031) was found. Further analysis of this partial gene sequence determined it was most closely related to the $V$. cholerae rifampin ADP-ribosyl transferase (aar) gene (\#CQB46884). Furthermore, both the int1 and aar sequences from clone no. 120 shared $100 \%$ sequence similarity with $V$. cholerae strain 116-17a plasmid pNDM-116-17 and strain 116-14 plasmid pNDM-116-14 (\#LN831185.1, \#LN831184). This result suggests that the transposon could have inserted in a native plasmid of $V$. cholerae or highly mobile element of chromosome I.

The transposon insertion in V. vulnificus clone no. 150, took place in chromosome II of V. vulnificus. The $961 \mathrm{nt}$ sequence from this clone has a $98 \%$ similarity with $V$. vulnificus chromosome II, with the closest match (98.8\%) to strain 06-2410 (\#CP046833). Unfortunately, this section of chromosome II (nucleotide position 76,000 to 78,000 ) is not well described. The clone no. 150 gene sequence shares $90 \%$ similarity with the undescribed domain-containing protein DUF368 and two V. vulnificus membrane proteins (\#SUQ28767, \#KFK50999). The next closest described protein, arginine/ornithine antiporter ArcD from V. vulnificus (\#AUL97231), shares 89.6\% homology with the corresponding amino acid sequence of clone no. 150.

\section{Discussion}

Our initial attempts to label the herein studied 30 Vibrio strains with RFP made use of a broad host range vector, a pBBR1MCS-4 based plasmid, previously modified to carry the DsRedExpress.cat gene cassettes [26] as per the protocol established by [23]. Unfortunately, this vector was only conjugable to one strain of $V$. cholerae (Vc-7) and two V. parahaemolyticus strains (Vp-14 and Vp-15). For the two $V$. parahaemolyticus strains, the plasmid was lost after two generations on non-selective MB agar at $28^{\circ} \mathrm{C}$ (data not shown). The pBBR1 vector appeared to be more stable in the one $V$. cholerae strain, however the few clones labelled with pBBR1MCS-4 were not tested further as they were clearly not performing as expected and this vector would be insufficient to RFP-tag more Vibrio strains in the future. Dunn et al. [4] also reports that broad-host range plasmids such as pBBR1 do not replicate in $V$. fischeri. This indicates that pBBR1MCS-4 plasmids are neither stable nor suitable for molecular manipulations of Vibrio species despite the wide range of use of the pBBR1MCS plasmid group in various environmental bacterial species [31].

This failure prompted us to investigate and produce a protocol compromise which sought to maximize the number of strains conjugable and minimize the modifications required between the numerous strains of the three tested species V. cholerae, V. parahaemolyticus, and V. vulnificus. Due to the poor performance of the pBBR1 plasmid in V. parahaemolyticus, we searched for a suitable suicide vector carrying fluorescent protein on a transposon. This led us to the study of Blanco and DiRita [30] who used the suicide vector pAG408 [22] to GFP-tag V. cholerae. The pAG408 vector was able to label six out of eight tested strains of $V$. vulnificus with GFP in a preliminary test. We report a modified "universal" protocol utilizing the pAG408 vector, and its constructed novel derivatives to carry RFP and eCFP (pCAT30 and pCAT14), to label all tested Vibrio strains.

Transposons have been used to genetically modify bacteria to not only carry GFP, but also to create insertion mutants and gene knockouts. Tn5 has been described as the "transposon with the broadest host range known" [24,32]. The new vectors constructed for this study (pCAT30 and pCAT14) have been modified from a Tn5-based suicide vector, pAG408 [22]. The newly constructed transposon regions encode for either DsRedExpress (pCAT30) or eCFP (pCAT14) and $\mathrm{Cm}^{\mathrm{R}}$, preceded by the E. coli 
constitutive lac promoter $\left(\mathrm{P}_{\mathrm{A} 1 / 04 / 03}\right)$. This new insert is flanked by the Tn5 sequences essential for transposition and the original $\mathrm{Gm}^{\mathrm{R}}$ gene from pAG408. Interestingly, Stretton and colleagues [33] reported that Tn5 is not transferable in Vibrio species and rather used Tn10. However, similar to our findings Blanco and DiRita [30] and Newland et al. [34], have used a Tn5-based transposon to label $V$. cholerae. Our data clearly demonstrate that Tn5-based transposons are transferable to the tested strains of Vibrio. In a preliminary trial, we also successfully GFP-tagged one strain of V. alginolyticus and two strains of $V$. aestuarianus with pAG408 (data not shown).

Promoter probes have long been useful to establish the conditional expression of a gene in response to a specific substance, growth condition, or for analyzing a sample or habitat for a substance or condition to which a particular gene is known to be responsive [35]. The vector pAG408 was designed as a promoter probe, thus we expected GFP expression to vary between labelled clones of the same strain. Despite the inclusion of an E. coli promoter in PCAT30 and pCAT14, we found that RFP was not evenly expressed between different clones of the same strain, indicating that $\mathrm{P}_{\mathrm{A} 1 / 04 / 03}$ might not be constitutively expressed in V. cholerae, V. parahaemolyticus, and V. vulnificus. Stretton et al. [33] reported that use of the E. coli lac and nptII promoters in Vibrio resulted in uniform levels of GFP expression across varying mutants. We believe further research regarding Vibrio constitutive promoters would greatly benefit future studies requiring bright fluorescence to be detected at a single-cell level. An increased range of promoter probes, like pCAT30, would be beneficial for such studies.

In other proteobacteria it has been found that the GFP or RFP accumulation in the cell can impose a fitness cost on the host [36], but no such cost has been reported in $V$. fischeri [4] or V. harveyi [18]. Tn5-based transposons insert randomly into chromosomal DNA, and may cause insertional inactivation of host genes, which in turn, may affect the expression of the inserted genes [37]. We did not find any strong indications that the GFP or RFP expression alone from pAG408 or pCAT30 were the cause of any deleterious phenotypic differences, and suggest that those clones which did not perform comparably to the WT strain were affected primarily by the positioning of the transposon insertion.

Drake et al. [38] reported that GFP-tagged V. vulnificus behaved comparably to the WT strain under most tested conditions, with the largest differences found under starvation and cold-adaptation conditions. Sawabe et al. [17] found that the percent of visibly fluorescent GFP-tagged Vibrio cells were greater at $15{ }^{\circ} \mathrm{C}$, than $20^{\circ} \mathrm{C}$ or $25^{\circ} \mathrm{C}$. This interesting observation was more pronounced when the cultures were grown aerobically, rather than anaerobically. We did not investigate thoroughly the impact of temperature on GFP or RFP expression, however, we did not observe a phenotypic difference in bacterial growth or expression levels in labelled clones grown at $20^{\circ} \mathrm{C}$ and $28^{\circ} \mathrm{C}$ (data not shown). Considering that $15^{\circ} \mathrm{C}$ is below the optimal growth temperature for many Vibrio strains, these previous observations warrant future study.

Similar studies that employed suicide vectors in Vibrio genetic modification successfully, also employed the use of $\lambda$ pir1-dependent R6K vectors transferable by RP4-based conjugation. Luo et al. [39] developed a genetic tool for generating quick and efficient deletion mutants in one $V$. cholerae, two $V$. parahaemolyticus, one $V$. vulnificus, and one $V$. alginolyticus strain using diaminopimelic-deficient E. coli (an E. coli strain incapable of growth on LB without the additional supplementation of thymidine and diaminopimelic acid). Additionally, Le Roux et al. [16] were able to use a transposon under the control of $\mathrm{P}_{\mathrm{BAD}}$ (an arabinose-inducible promoter) to select for gene knock-out mutants in $V$. splendidus and $V$. cholerae. In both studies, specialized E. coli strains, like E. coli ST18, were utilized to select for transconjugants under higher growth temperatures ( 28 to $37^{\circ} \mathrm{C}$ ) within two days.

We report a conjugation method with a relatively high conjugation efficiency of $0.02-0.08 \%$, across 30 different strains of $V$. cholerae, V. parahaemolyticus, and V. vulnificus. In other studies, the efficiency of conjugation is not explicitly reported, possibly because the number of colonies on the selective plates marks only the beginning of finding a suitable tagged clone for future work. Luo et al. [39] reported an initial 30-70 colonies on the $10^{0}$ dilution plate from which, 3-12 positives were picked out of a random 20. In the current study, while all possible transconjugants were not 
tested, we found that through further selection on $\mathrm{MB}$ and $\mathrm{Gm}$ or $\mathrm{MB}$ and $\mathrm{Cm}$, out of 6-8 colonies picked from the conjugation, between 3-6 clones fluoresced and could be further tested for comparison to the WT.

Previously, plasmids pKV111 and pKV112 were used to test a universal conjugation method for 39 Vibrio species (represented by 43 strains) [17]. The efficiency was not reported for that study, but all 39 tested species produced transconjugants on selective plates. The E. coli donor was counter-selected against using MB media supplemented with $0.5 \%$ sodium alginate and incubating the plates for at least four days at $15{ }^{\circ} \mathrm{C}$ [17]. Interestingly, the authors reported that despite the use of a host-maintained plasmid, they found that GFP expression was not even across cultures, similar to the current study. Sawabe et al. [17] reported their labelled clones could be used in experiments under starvation conditions for up to four days but are likely to remain detectable for longer periods under selection pressure. Although plasmids may be easily maintained in single-strain bacterial cultures under controlled conditions (typically through the use of antibiotic selection), they are frequently unstable when the strain is grown in the absence of selection, and this instability may be exacerbated when the host bacteria must compete with other organism in natural niches [24], limiting their use in competitive analyses.

Dunn et al. [4] modified a native $V$. fischeri plasmid to carry GFP and dsRed-derivatives for future Vibrio FP-tagging. These derivative vectors appear to be much more stably maintained in Vibrio than pKV111. In conjunction with a standard conjugation protocol [5], these vectors have been used to label multiple Vibrio species, including V. harveyi and V. parahaemolyticus [18,19]. The lifespan of this plasmid and its associated derivatives varies per study. Travers et al. [18] found that after seven days of nonselective monoculture, at least $80 \%$ of the bacteria (GFP-tagged $V$. harveyi) retained fluorescence, and at least 12 days of continuous culture were needed before counting less than $20 \%$ of GFP-expressing cells. Gobi et al. [19] reported that after $24 \mathrm{~h}$ in a competitive environment, the GFP was still evident in their labelled V. parahaemolyticus strain. In the current study, our experiments in NSW indicate that the pCAT30 and PCAT14 transposons are stably inserted into the host and functions well as a selective marker under nutrient-limited and non-selective culturing conditions for at least $72 \mathrm{~h}$, although we believe the transposon to be stably inherited and stably expressed for the lifetime of the clones.

The insertion locations for two clones (no. 120-V. cholerae, and no. 150-V. vulnificus) were determined. The insertion in the $V$. vulnificus clone no. 150 occurred in chromosome II. While the genes of interest with closest similarity to our sequence remain uncharacterized, it appears to encode for a membrane-associated protein, possibly an arginine/ornithine antiporter gene. We speculate that the insertion in the $V$. cholerae clone no. 120 likely occurred in a native plasmid due to the high sequence similarity with the intI and aar genes found on other $V$. cholerae plasmids [40], though at this time we cannot rule out that instead the transposon inserted into a highly mobile element of chromosome I encoding these genes. Additionally, if the transposon inserted into a native plasmid of $V$. cholerae, isolation and characterization of this plasmid and its conjugable ability in other Vibrios could add to the genetic tool kit for this genus, similar to the study of [4].

Despite the significant impact of $V$. cholerae, V. parahaemolyticus, and V. vulnificus on human health and aquaculture, comparatively little is known about their genetic accessibility. This study aimed to develop a set of genetic tools and a universal conjugation protocol specifically to target $V$. cholerae, V. parahaemolyticus, and V. vulnificus species, although it is likely these tools and method can be applied to other Vibrio species and other marine bacteria. To conclude, we developed two additional suicide vectors carrying R6K-based Tn 5 mini-transposons for use in multi-labelling (GFP, RFP, and eCFP) of 30 different strains of V. cholerae, V. parahaemolyticus, and V. vulnificus, which were primarily of environmental origin. By using a 5-ALA auxotroph mutant $E$. coli, we demonstrated a quick and easy method for counterselection that allowed us to obtain Vibrio transconjugants on MB or LB media at $28^{\circ} \mathrm{C}$ within one to two days for 29 out of 30 of the tested Vibrios. The transconjugation efficiency averaged across each species was $0.02 \%$ ( $V$. cholerae), $0.05 \%$ ( V. parahaemolyticus), and $0.08 \%$ ( $V$. vulnificus). We have shown that these vectors have the potential to be used for either gene expression 
studies or the stable labelling of $V$. cholerae, $V$. parahaemolyticus, and $V$. vulnificus, thereby increasing the genetic toolbox available for these key pathogenic Vibrio species.

Author Contributions: Conceptualization: C.A.T. and M.S.U.; methodology, validation, formal analysis, writing-original draft preparation: C.A.T.; supervision: M.S.U. All authors have read and agreed to the published version of the manuscript.

Funding: This research was funded by the Deutsche Forschungsgemeinschaft (DFG), grant number UL169/7-1.

Acknowledgments: We would like to kindly thank Maike Last for her assistance with the cloning and sequencing experiments to determine the transposon location.

Conflicts of Interest: The authors declare no conflict of interest.

\section{References}

1. Norsworthy, A.N.; Visick, K.L. Gimme shelter: How Vibrio fischeri successfully navigates an animal's multiple environments. Front. Microbiol. 2013, 4, 356. [CrossRef] [PubMed]

2. Baker-Austin, C.; Trinanes, J.A.; Salmenlinna, S.; Löfdahl, M.; Siitonen, A.; Taylor, N.G.H.; Martinez-Urtaza, J. Heat Wave-Associated Vibriosis, Sweden and Finland, 2014. Emerg. Infect. Dis. 2016, 22, 1216-1220. [CrossRef] [PubMed]

3. Daniels, N.A.; MacKinnon, L.; Bishop, R.; Altekruse, S.; Ray, B.; Hammond, R.M.; Thompson, S.; Wilson, S.; Bean, N.H.; Griffin, P.M.; et al. Vibrio parahaemolyticus infections in the United States, 1973-1998. J. Infect. Dis. 2000, 181, 1661-1666. [CrossRef] [PubMed]

4. Dunn, A.K.; Millikan, D.S.; Adin, D.M.; Bose, J.L.; Stabb, E.V. New rfp- and pES213-Derived Tools for Analyzing Symbiotic Vibrio fischeri Reveal Patterns of Infection and lux Expression in Situ. Appl. Environ. Microbiol. 2006, 72, 802-810. [CrossRef]

5. Stabb, E.V.; Ruby, E.G. RP4-based plasmids for conjugation between Escherichia coli and members of the Vibrionaceae. Methods Enzymol. 2002, 358, 413-426.

6. Zeaiter, Z.; Mapelli, F.; Crotti, E.; Borin, S. Methods for the genetic manipulation of marine bacteria. Electron. J. Biotechnol. 2018, 33, 17-28. [CrossRef]

7. Hamashima, H.; Nakano, T.; Tamura, S.; Arai, T. Genetic Transformation of Vibrio parahaemolyticus, Vibrio alginolyticus, and Vibrio cholerae Non O-1 with Plasmid DNA by Electroporation. Microbiol. Immunol. 1990, 34, 703-708. [CrossRef]

8. Klevanskaa, K.; Bier, N.; Stingl, K.; Strauch, E.; Hertwig, S. PVv3, a New Shuttle Vector for Gene Expression in Vibrio vulnificus. Appl. Environ. Microbiol. 2014, 80, 1477-1481. [CrossRef]

9. Marcus, H.; Ketley, J.M.; Kaper, J.B.; Holmes, R.K. Effects of DNase production, plasmid size, and restriction barriers on transformation of Vibrio cholerae by electroporation and osmotic shock. FEMS Microbiol. Lett. 1990, 68, 149-154. [CrossRef]

10. Weinstock, M.; Hesek, E.; Wilson, C.; Gibson, D. Vibrio natriegens as a fast-growing host for molecular biology. Nat. Methods 2016, 13. [CrossRef]

11. Chen, Y.; Dai, J.; Morris, J.G.; Johnson, J.A. Genetic analysis of the capsule polysaccharide (K antigen) and exopolysaccharide genes in pandemic Vibrio parahaemolyticus O3:K6. BMC Microbiol. 2010, 10, 274. [CrossRef] [PubMed]

12. Gulig, P.A.; Tucker, M.S.; Thiaville, P.C.; Joseph, J.L.; Brown, R.N. USER Friendly Cloning Coupled with Chitin-Based Natural Transformation Enables Rapid Mutagenesis of Vibrio vulnificus. Appl. Environ. Microbiol. 2009, 75, 4936-4949. [CrossRef] [PubMed]

13. Marvig, R.L.; Blokesch, M. Natural transformation of Vibrio cholerae as a tool-optimizing the procedure. BMC Microbiol. 2010, 10, 155. [CrossRef]

14. Meibom, K.L.; Blokesch, M.; Dolganov, N.A.; Wu, C.-Y.; Schoolnik, G.K. Chitin induces natural competence in Vibrio cholerae. Science 2005, 310, 1824-1827. [CrossRef]

15. Aune, T.E.V.; Aachmann, F.L. Methodologies to increase the transformation efficiencies and the range of bacteria that can be transformed. Appl. Microbiol. Biotechnol. 2010, 85, 1301-1313. [CrossRef]

16. Le Roux, F.; Binesse, J.; Saulnier, D.; Mazel, D. Construction of a Vibrio splendidus Mutant Lacking the Metalloprotease Gene vsm by Use of a Novel Counterselectable Suicide Vector. Appl. Environ. Microbiol. 2007, 73, 777-784. [CrossRef] [PubMed] 
17. Sawabe, T.; Fukui, Y.; Stabb, E.V. Simple conjugation and outgrowth procedures for tagging vibrios with GFP, and factors affecting the stable expression of the gfp tag. Lett. Appl. Microbiol. 2006, 43, 514-522. [CrossRef]

18. Travers, M.-A.; Barbou, A.; Le Goïc, N.; Huchette, S.; Paillard, C.; Koken, M. Construction of a stable GFP-tagged Vibrio harveyi strain for bacterial dynamics analysis of abalone infection. FEMS Microbiol. Lett. 2008, 289, 34-40. [CrossRef]

19. Gobi, N.; Malaikozhundan, B.; Sekar, V.; Shanthi, S.; Vaseeharan, B.; Jayakumar, R.; Nazar, A.K. GFP tagged Vibrio parahaemolyticus Dahv2 infection and the protective effects of the probiotic Bacillus licheniformis Dahb1 on the growth, immune and antioxidant responses in Pangasius hypophthalmus. Fish Shellfish Immunol. 2016, 52, 230-238. [CrossRef]

20. Nyholm, S.V.; Stabb, E.V.; Ruby, E.G.; McFall-Ngai, M.J. Establishment of an animal-bacterial association: Recruiting symbiotic vibrios from the environment. Proc. Natl. Acad. Sci. USA 2000, 97, 10231-10235. [CrossRef]

21. Cabello, F.C.; Espejo, R.; Hernandez, M.C.; Rioseco, M.L.; Ulloa, J.; Vergara, J.A. Vibrio parahaemolyticus O3:K6 Epidemic Diarrhea, Chile, 2005. Emerg. Infect. Dis. 2007, 13, 655-656. [CrossRef] [PubMed]

22. Suarez, A.; Güttler, A.; Strätz, M.; Staendner, L.H.; Timmis, K.N.; Guzmán, C.A. Green fluorescent protein-based reporter systems for genetic analysis of bacteria including monocopy applications. Gene 1997, 196, 69-74. [CrossRef]

23. Sonnenschein, E.C.; Gärdes, A.; Seebah, S.; Torres-Monroy, I.; Grossart, H.-P.; Ullrich, M.S. Development of a genetic system for Marinobacter adhaerens HP15 involved in marine aggregate formation by interacting with diatom cells. J. Microbiol. Methods 2011, 87, 176-183. [CrossRef]

24. Herrero, M.; de Lorenzo, V.; Timmis, K.N. Transposon vectors containing non-antibiotic resistance selection markers for cloning and stable chromosomal insertion of foreign genes in gram-negative bacteria. J. Bacteriol. 1990, 172, 6557-6567. [CrossRef] [PubMed]

25. Fujino, T.; Okuno, Y.; Nakada, D.; Aoyama, A.; Fukai, K.; Mukai, T.; Ueho, T. On the bacteriological examination of shirasu-food poisoning. Med. J. Osaka Univ. 1953, 4, 299-304.

26. Stahl, A. Interaction of the Marine Bacterium Marinobacter Adhaerens HP15 with the Diatom Thalassiosira Weissflogii Analyzed by Proteomics Approaches. Ph.D. Thesis, Jacobs University Bremen, Bremen, Germany, 2016.

27. Lambertsen, L.; Sternberg, C.; Molin, S. Mini-Tn7 transposons for site-specific tagging of bacteria with fluorescent proteins. Environ. Microbiol. 2004, 6, 726-732. [CrossRef]

28. Gonzales, M.F.; Brooks, T.; Pukatzki, S.U.; Provenzano, D. Rapid protocol for preparation of electrocompetent Escherichia coli and Vibrio cholerae. JoVE J. Vis. Exp. 2013, e50684.

29. Neogi, S.B.; Chowdhury, N.; Asakura, M.; Hinenoya, A.; Haldar, S.; Saidi, S.M.; Kogure, K.; Lara, R.J.; Yamasaki, S. A highly sensitive and specific multiplex PCR assay for simultaneous detection of Vibrio cholerae, Vibrio parahaemolyticus and Vibrio vulnificus. Lett. Appl. Microbiol. 2010, 51, 293-300. [CrossRef]

30. Blanco, L.P.; DiRita, V.J. Bacterial-associated cholera toxin and GM1 binding are required for transcytosis of classical biotype Vibrio cholerae through an in vitro M cell model system. Cell. Microbiol. 2006, 8, 982-998. [CrossRef]

31. Kovach, M.; Phillips, R.; Elzer, P.; Roop, R.; Perterson, K. pBBR1MCS: A broad-host-range cloning vector. BioTechniques 1994, 16, 800-802.

32. Berg, D.E. Transposon Tn5. In Mobile DNA; Howe, M.M., Ed.; American Society for Microbiology: Washington, DC, USA, 1989; pp. 185-210.

33. Stretton, S.; Techkarnjanaruk, S.; McLennan, A.M.; Goodman, A.E. Use of green fluorescent protein to tag and investigate gene expression in marine bacteria. Appl. Environ. Microbiol. 1998, 64, 2554-2559. [CrossRef] [PubMed]

34. Newland, J.W.; Green, B.A.; Holmes, R.K. Transposon-mediated mutagenesis and recombination in Vibrio cholerae. Infect. Immun. 1984, 45, 428-432. [CrossRef]

35. Leveau, J.H.J.; Lindow, S.E. Predictive and Interpretive Simulation of Green Fluorescent Protein Expression in Reporter Bacteria. J. Bacteriol. 2001, 183, 6752-6762. [CrossRef] [PubMed]

36. Rang, C.; Galen, J.E.; Kaper, J.B.; Chao, L. Fitness cost of the green fluorescent protein in gastrointestinal bacteria. Can. J. Microbiol. 2003, 49, 531-537. [CrossRef] [PubMed] 
37. Koch, B.; Jensen, L.E.; Nybroe, O. A panel of Tn7-based vectors for insertion of the gfp marker gene or for delivery of cloned DNA into Gram-negative bacteria at a neutral chromosomal site. J. Microbiol. Methods 2001, 45, 187-195. [CrossRef]

38. Drake, S.L.; Elhanafi, D.; Bang, W.; Drake, M.A.; Green, D.P.; Jaykus, L.A. Validation of a Green Fluorescent Protein-Labeled Strain of Vibrio vulnificus for Use in the Evaluation of Postharvest Strategies for Handling of Raw Oysters. Appl. Environ. Microbiol. 2006, 72, 7205-7211. [CrossRef]

39. Luo, P.; He, X.; Liu, Q.; Hu, C. Developing Universal Genetic Tools for Rapid and Efficient Deletion Mutation in Vibrio Species Based on Suicide T-Vectors Carrying a Novel Counterselectable Marker, vmi480. PLoS ONE 2015, 10. [CrossRef]

40. Partridge, S.R.; Brown, H.J.; Stokes, H.W.; Hall, R.M. Transposons Tn1696 and Tn21 and their integrons In4 and In2 have independent origins. Antimicrob. Agents Chemother. 2001, 45, 1263-1270. [CrossRef]

Publisher's Note: MDPI stays neutral with regard to jurisdictional claims in published maps and institutional affiliations.

(C) 2020 by the authors. Licensee MDPI, Basel, Switzerland. This article is an open access article distributed under the terms and conditions of the Creative Commons Attribution (CC BY) license (http://creativecommons.org/licenses/by/4.0/). 